\title{
Water-Enhanced Flux Changes under Dynamic Temperatures in the Vertical Vapor-Phase Diffusive Transport of Volatile Organic Compounds in Near-Surface Soil Environments
}

\author{
Asma Akter Parlin ${ }^{1}$, Monami Kondo ${ }^{1}$, Noriaki Watanabe ${ }^{1, * \mathbb{C}}$, Kengo Nakamura ${ }^{1}$, Mizuki Yamada ${ }^{2}$, \\ Jiajie Wang ${ }^{1}$ and Takeshi Komai ${ }^{1}$ \\ 1 Department of Environmental Studies for Advanced Society, Graduate School of Environmental Studies, \\ Tohoku University, Sendai 9808579, Japan; asma.akter.parlin.r6@dc.tohoku.ac.jp (A.A.P.); \\ monami.kondo.p3@dc.tohoku.ac.jp (M.K.); kengo.nakamura.e8@tohoku.ac.jp (K.N.); \\ wang.jiajie.e4@tohoku.ac.jp (J.W.); takeshi.komai.e7@tohoku.ac.jp (T.K.) \\ 2 Department of Mechanical and Aerospace Engineering, School of Engineering, Tohoku University, \\ Sendai 9808579, Japan; mizuki.yamada.r3@dc.tohoku.ac.jp \\ * Correspondence: noriaki.watanabe.e6@tohoku.ac.jp
}

Citation: Parlin, A.A.; Kondo, M.; Watanabe, N.; Nakamura, K.; Yamada, M.; Wang, J.; Komai, T.

Water-Enhanced Flux Changes under Dynamic Temperatures in the Vertical Vapor-Phase Diffusive Transport of Volatile Organic Compounds in Near-Surface Soil Environments. Sustainability 2021, 13, 6570. https:/ / doi.org/10.3390/su13126570

Academic Editors: Raluca Ciuraru, Letizia Abis and Julien Kammer

Received: 30 April 2021

Accepted: 7 June 2021

Published: 9 June 2021

Publisher's Note: MDPI stays neutral with regard to jurisdictional claims in published maps and institutional affiliations.

Copyright: (c) 2021 by the authors. Licensee MDPI, Basel, Switzerland. This article is an open access article distributed under the terms and conditions of the Creative Commons Attribution (CC BY) license (https:// creativecommons.org/licenses/by/ $4.0 /)$.

\begin{abstract}
The quantitative understanding of the transport behavior of volatile organic compounds (VOCs) in near-surface soils is highly important in light of the potential impacts of soil VOC emissions on the air quality and climate. Previous studies have suggested that temperature changes affect the transport behavior; however, the effects are not well understood. Indeed, much larger changes in the VOC flux under in situ dynamic temperatures than those expected from the temperature dependence of the diffusion coefficients of VOCs in the air have been suggested but rarely investigated experimentally. Here, we present the results of a set of experiments on the upward vertical vaporphase diffusive transport of benzene and trichloroethylene (TCE) in sandy soils with water contents ranging from an air-dried value to $10 \mathrm{wt} \%$ during sinusoidal temperature variation between 20 and $30{ }^{\circ} \mathrm{C}$. In all experiments, the flux from the soil surface was correlated with the temperature, as expected. However, the changes in flux under wet conditions were unexpectedly large and increased with increasing water content; they were also larger for TCE, the volatility of which depended more strongly on the temperature. Additionally, the larger flux changes were accompanied by a recently discovered water-induced inverse correlation between temperature and flux into the overlying soil. These results demonstrated that the flux changes of VOCs under dynamic temperatures could be increased by volatilization-dissolution interactions of VOCs with water. Future extensive studies on this newly discovered phenomenon would contribute to a better understanding of the impacts of soil VOC emissions on the air quality and climate.
\end{abstract}

Keywords: volatile organic compounds; water; soils; diffusive transport; flux; temperature

\section{Introduction}

Volatile organic compounds (VOCs) emitted into the atmosphere from both anthropogenic and biogenic sources are of great interest because they participate in atmospheric photochemical reactions that contribute to the formation of secondary compounds such as ozone and secondary organic aerosols [1-3]. VOC emissions also mitigate climate change through the formation of secondary organic aerosols and are involved in climate feedback processes; however, the effects are still very uncertain. Vegetation and soil are significant sources of emissions for various VOCs. In addition to the large impact of vegetation, the importance of soil for the global balance of VOCs, where soils can act as both sources and sinks for VOCs, has also been highlighted [4,5]. Therefore, a global assessment of VOC emissions should provide quantitative information on soil VOC emissions, for example, changes in the VOC flux owing to gas-phase vertical transport in dynamic near-surface 
soil environments, and advance our understanding of the impact of soil VOC emissions on air quality and climate.

The transport behavior of VOCs such as petroleum hydrocarbons and chlorinated hydrocarbon compounds in near-surface soils has been extensively studied because these relatively long-lived VOCs pose a serious environmental threat owing to their large-scale production and extensive use in manufacturing $[1,6,7]$. VOC vapors can migrate from contaminated near-surface soils into buildings when they underlie building foundations, raising indoor VOC concentrations above those in outdoor environments [8,9]. The inhalation of VOC vapors indoors is considered to be a significant exposure pathway at VOC-contaminated sites and poses a severe hazard to human health [10-12]. Several factors influence the VOC vapor transport behavior $[13,14]$. For instance, previous studies have reported that VOC transport is significantly influenced by soil temperature [13] and that diffusive transport rates of VOCs are higher at higher temperatures in static temperature environments [15-18]. However, owing to the dynamic nature of these environments and/or heterogeneities in the characteristics of subsurface soils, the VOC vapor transport behavior is likely to be unexpected or counterintuitive.

Previous field observations of near-surface soils at depths of up to $3 \mathrm{~m}$ suggested an inverse correlation between subsurface soil temperature and vertical VOC flux [13]. Although the in situ trichloroethylene (TCE) flux was positively correlated with the in situ temperature at shallower locations, an inverse correlation was observed at deeper locations. Additionally, the flux changes were generally larger than those expected from the temperature dependence of the diffusion coefficient of TCE in the air (Figure 1), where the in situ flux could increase by a factor of more than two and could decrease to nearzero or negative values. These unexpected and counterintuitive flux changes may be related to changes in the indoor VOC concentrations reported by another field study [14]. That is, changes in the indoor tetrachloroethylene (PCE) concentration (changes between 0.01-1 $\mu \mathrm{g} / \mathrm{L}$ for one of the two sites studied and between $0.01-0.1 \mu \mathrm{g} / \mathrm{L}$ for the other site) were closely correlated with the soil temperatures at relatively shallow depths but not with deeper soil temperatures (in a depth range of approximately $3 \mathrm{~m}$ ) and could exhibit a 2-fold increase even during a normal increase in soil temperature (e.g., $5^{\circ} \mathrm{C}$ ), which is not predicted by the temperature dependence of the diffusion coefficient of PCE in the air (Figure 1). However, to the best of our knowledge, these inverse correlations and unexpectedly large changes in dynamic temperature environments have rarely been investigated in the laboratory, as most laboratory experiments on gas-phase diffusive VOC transport in soils have been conducted at a constant temperature [19-27].

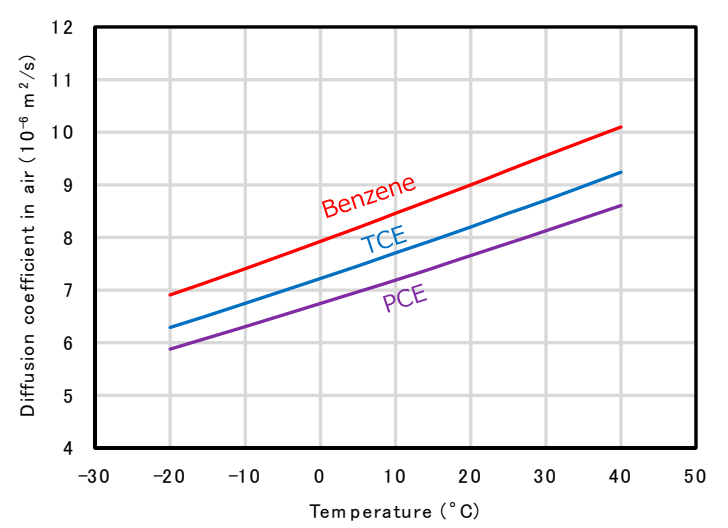

Figure 1. Temperature dependence of diffusion coefficients of trichloroethylene (TCE), tetrachloroethylene (PCE), and benzene in the air [28].

In the few laboratory-based studies that have considered dynamic environments in near-surface soils, positive correlations were generally found between temperature and VOC flux at the soil surface [29-31]. In experiments at a mesocosm-scale simulator facility, soil surface temperature changes were driven by diurnal temperature variations 
$\left(18-24^{\circ} \mathrm{C}\right)[30]$. This study showed a correlation between the soil surface temperature and the total hydrocarbon flux from the soil surface. Another study investigated the effects of field conditions such as temperature and relative humidity above the soil surface [29]. In the experiments, the temperature changed diurnally, whereas the relative humidity was maintained at a relatively constant value. The benzene flux from the soil surface was also found to be correlated with the temperature. However, these studies did not address the unexpected or counterintuitive effects of temperature on VOC flux. Our very recent study [31] revealed an inverse correlation using experiments on the upward vertical vapor-phase diffusive transport of benzene in sandy soils at near-zero and $10 \mathrm{wt} \%$ water contents during sinusoidal temperature variation between 20 and $30^{\circ} \mathrm{C}$. In the experiments, the flux from the soil surface was correlated with temperature, whereas the flux into the overlying soil showed an inverse correlation. The inverse correlation appeared in response to the condensation and volatilization of water, and the strength of the inverse correlation was independent of sand grain size but was larger at higher water content. Importantly, considering the temperature dependence of the diffusion coefficient of benzene in the air (Figure 1), unexpectedly large flux changes (e.g., by a factor of more than two) also occurred in the experiments, although this point was not noticed in that study.

The literature review provided here reveals that both the inverse correlation and unexpectedly large changes have been observed simultaneously, and the inverse correlation has been observed in wet soils. These facts suggest that larger flux changes under dynamic temperatures occur for many types of VOCs in wet soils and that the strength of this effect increases with increasing water content. In this study, therefore, we examine this hypothesis via laboratory experiments on the upward vertical vapor-phase diffusive transport of benzene and TCE in sandy soils with different water contents ranging from an air-dried condition to $10 \mathrm{wt} \%$ during sinusoidal temperature variations between 20 and $30{ }^{\circ} \mathrm{C}$, where moderately high effective diffusion coefficients for the sandy soils prevent too fast or too slow flux changes to observe. We first describe an experimental method of investigating vertical vapor-phase diffusive transport of VOCs through the soil, which enables separate and continuous measurements of the VOC concentration and flux at both the bottom and top of the soil sample under both static and dynamic temperature. We then present the results of experiments at a static temperature $\left(25^{\circ} \mathrm{C}\right)$ and dynamic temperature $\left(25 \pm 5^{\circ} \mathrm{C}\right)$ on the diffusive transport of benzene through a sandy soil sample with a water content of $10 \mathrm{wt} \%$ to verify that the characteristic results showing larger flux changes under dynamic temperatures are not obtained under static temperature. Next, we present the results of a set of dynamic temperature experiments on the diffusive transport of benzene and TCE in air-dried samples and at water contents of 5 and $10 \mathrm{wt} \%$ to reveal the effects of water content and VOC type on the flux. Finally, the possible mechanism of the larger flux changes is discussed in light of the experimental results.

\section{Materials and Methods}

\subsection{Experimental System}

An experimental system for the vertical vapor-phase diffusive transport of VOC through a soil sample was developed using an aluminum column, as illustrated in Figure 2. The VOC concentration, temperature, and pressure could be continuously measured in both the bottom and top spaces of the column under static and dynamic temperatures. The inner diameter and length of the column were 4.4 and $28.6 \mathrm{~cm}$, respectively. A soil sample, approximately $10 \mathrm{~cm}$ in length containing a prescribed amount of water, was placed in the middle of the column; it was supported at its lower end by a $1 \mathrm{~mm}$ thick stainless-steel-sintered filter and capped at its upper end by another filter on which a $50 \mathrm{~g}$ weight was placed to stabilize the soil. 




Figure 2. Experimental system for the vertical vapor-phase diffusive transport of a volatile organic compounds (VOC) through a soil sample and vertical X-ray CT slice images of air-dried silica sand.

The top and bottom spaces of the column were monitored using thermocouples, pressure sensors, and portable gas detectors (GX-6000, Riken Keiki Co., Ltd., Tokyo, Japan). The gas detectors were equipped with a pump that allowed the continuous circulation of gas between the detector and the top or bottom space; they measured the VOC concentration every $5 \mathrm{~min}$ using a photoionization detector (PID). The pump produced no detectable pressure difference $(<0.1 \mathrm{kPa})$ between the bottom and top spaces. Therefore, advective VOC transport caused by pumping was unlikely. During the experiment, the column and its sensors and detectors were placed in a temperature-controlled air bath capable of operating between -15 and $50{ }^{\circ} \mathrm{C}$.

\subsection{Experimental Procedures}

Air-dried natural silica sand (221.4 g; Toyoura Keiseki Kogyo Co., Ltd., Yamaguchi, Japan) with a water content of approximately $0.3 \mathrm{wt} \%$ was first homogeneously packed into the column, as shown in the vertical X-ray computed tomography (CT) slice images in Figure 2. The images were captured at an X-ray tube voltage of $120 \mathrm{kV}, \mathrm{X}$-ray tube current of $150 \mu \mathrm{A}$, and voxel size of $40 \times 40 \times 40 \mu \mathrm{m}^{3}$ using a microfocus X-ray CT system (ScanXmate-D225RSS270, Comscantecno Co., Ltd., Kanagawa, Japan), where a lighter color in the image corresponded to a higher density. Although it is difficult to identify the shape of each grain of the silica sand in the figure because of the voxel size employed, the homogeneity of the packing was confirmed by the homogenous color in the figure. As this sand has been widely used in Japan for various research purposes, its characteristics are well documented in the literature [32-36]. It typically contains $\geq 90 \%$ silica, rarely contains organic impurities, and is moderately rounded and uniformly graded, with particle sizes ranging from 0.074 to $0.35 \mathrm{~mm}$, and mean grain size of $0.22 \mathrm{~mm}$. To prepare wet soil samples, the prescribed amount of water (see Section 2.3) was added to the top face of the soil sample using a syringe, and the column was left to rest overnight. As no water dropped from the soil sample to the bottom space, we concluded that all the added water was naturally distributed in the soil sample.

After the temperatures in the bottom and top spaces reached $25^{\circ} \mathrm{C}$, approximately $3 \mathrm{~mL}$ of either benzene gas or TCE gas were injected into the bottom space of the column through a gas detector circulation tube connected to a syringe. No detectable pressure changes were observed during VOC injection. VOC vapor was extracted from the headspace of a sealed $10 \mathrm{~mL}$ vial containing either $0.5 \mathrm{~mL}$ of liquid benzene $(99.7 \%$ purity, Wako Pure Chemical Industry, Ltd., Osaka, Japan) or liquid TCE (99.5\% purity, Kanto 
Chemical Co., Inc., Tokyo, Japan), which were heated to 60 or $68^{\circ} \mathrm{C}$, respectively. The boiling point and solubility in water at $25^{\circ} \mathrm{C}$ are $80.1{ }^{\circ} \mathrm{C}$ and $22.8 \mathrm{mmol} / \mathrm{L}$, respectively, for benzene and $87.2{ }^{\circ} \mathrm{C}$ and $8.4 \mathrm{mmol} / \mathrm{L}$, respectively, for TCE [28,37]. The diffusion coefficients of benzene and TCE at various temperatures are shown in Figure 1, where benzene has slightly higher diffusion coefficients.

The VOC concentration, temperature, and pressure in both the bottom and top spaces were measured for $100 \mathrm{~min}$ at either a constant temperature of $25^{\circ} \mathrm{C}$ or under sinusoidal temperature variations between 20 and $30{ }^{\circ} \mathrm{C}$, i.e., $25 \pm 5{ }^{\circ} \mathrm{C}$ (Figure 3). During the measurement, the VOC concentrations in the bottom and top spaces decreased and increased, respectively, with time owing to upward diffusive transport of the VOC without a detectable change in pressure; therefore, the pressure data are not presented in the results.

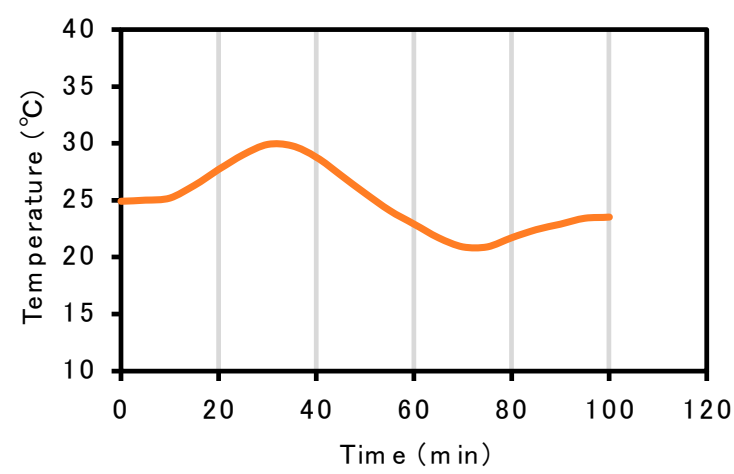

Figure 3. Schematic diagram representing the temperature changes in the dynamic temperature experiments.

The changes in the VOC concentration in the bottom and top spaces of the column (with known dimensions) were used to estimate the VOC fluxes into and from the soil sample, respectively, as follows:

$$
\begin{gathered}
J_{v b t m, i}=\frac{\left(C_{v b t m, i-1}-C_{v b t m, i+1}\right) \times 10^{-3}}{22.4} \cdot \frac{273}{273+T} \cdot \frac{L_{b t m}}{2 \Delta t} \text { and } \\
J_{v t o p, i}=\frac{\left(C_{v t o p, i+1}-C_{v t o p, i-1}\right) \times 10^{-3}}{22.4} \cdot \frac{273}{273+T} \cdot \frac{L_{t o p}}{2 \Delta t},
\end{gathered}
$$

where $J_{v b t m, i}$ and $J_{v t o p, i}$ are the bottom and top VOC fluxes $\left(\mathrm{mol} / \mathrm{m}^{2} / \mathrm{s}\right)$, respectively, at measurement time $i ; C_{v b t m, i+1}, C_{v b t m, i-1}, C_{v t o p, i+1}$, and $C_{v t o p, i-1}$ are the bottom and top VOC concentrations (ppm) at measurement times $i+1$ and $i-1$, respectively; $T$ is the temperature $\left({ }^{\circ} \mathrm{C}\right) ; L_{b t m}$ and $L_{t o p}$ are the lengths $(\mathrm{m})$ of the bottom and top spaces, respectively; and $\Delta t$ is the measurement interval ( $5 \mathrm{~min}=300 \mathrm{~s}$ ). In the above equations, the change of the VOC concentration during $2 \Delta t$ rather than $\Delta t$ was used to reduce the influence of a nonessential concentration change which is only a temporary change.

The temperature changes in the average value of $\left(25^{\circ} \mathrm{C}\right) \pm 5^{\circ} \mathrm{C}$, and the decreasing VOC concentration used in this study were based on a previous field study [13], which showed that unexpectedly large flux changes with soil temperature changes occurred under these conditions, accompanied by an inverse correlation between temperature and VOC flux. Moreover, we note that a preliminary measurement of the temperature change at the center of the sand-packed column confirmed that the temperature change was almost the same at any location within the column, which replicated the approximately depthindependent temperature change at a depth range of up to $3 \mathrm{~m}$ (except at the soil surface), as reported in the previous field study [13]. For this reason, only the data for the bottom temperature are presented in the results. 


\subsection{Experimental Conditions}

Five experiments (Runs 1-5) were conducted, as listed in Table 1. In Run 1, benzene was used at a water content of $10 \mathrm{wt} \%$ under static temperature. In Runs 2, 3, and 4, benzene was used at water contents of $10 \mathrm{wt} \%, 5 \mathrm{wt} \%$, and the air-dried value $(\sim 0.3 \mathrm{wt} \%)$, respectively, under dynamic temperatures. In Run 5, TCE was used for comparison with Run 3 at a water content of $5 \mathrm{wt} \%$ under dynamic temperatures. The amount of water added to obtain water contents of 10 and $5 \mathrm{wt} \%$ were 22 and $11 \mathrm{~g}$, respectively.

Table 1. Volatile organic compound (VOC), water content, and temperature in each experiment.

\begin{tabular}{cccc}
\hline Experiment & VOC & Water Content (wt\%) & Temperature \\
\hline Run 1 & Benzene & 10 & Static \\
Run 2 & Benzene & 10 & Dynamic \\
Run 3 & Benzene & 5 & Dynamic \\
Run 4 & Benzene & Air-dried $(\sim 0.3)$ & Dynamic \\
Run 5 & TCE & 5 & Dynamic \\
\hline
\end{tabular}

\section{Results}

\subsection{Larger Flux Changes Under Dynamic Temperatures}

Figure 4 compares the changes in benzene concentration and the corresponding fluxes in the bottom (inlet) and top (outlet) spaces in the static and dynamic temperature experiments, Run 1 (Figure 4a) and Run 2 (Figure 4b), respectively. The flux value at each time presented herein is represented by a ratio of the observed flux value to the largest observed flux value, where the largest observed flux value is presented in each figure panel. In Run 1, under static temperature, the bottom VOC concentration decreased with time as a result of VOC intrusion into the soil sample. In addition, the top VOC concentration increased owing to VOC emission from the soil sample. Consequently, the difference between the bottom and top VOC concentrations decreased with time, and the bottom and top VOC fluxes decreased overall. The bottom VOC flux tended to be larger than the top VOC flux owing to VOC infiltration of ineffective pore spaces and/or the dissolution of VOC in pore water within the soil. These characteristics were observed in all the experiments in this study. As demonstrated here, the VOC fluxes under static temperature showed no significant fluctuation with time, which confirmed that the experimental system was suitable for the investigation of the effects of temperature on VOC flux. In particular, the effects were identified more easily from the changes in VOC flux after approximately 30 min because the earlier VOC flux changes were largely the result of the larger and more rapid changes in the concentration difference between the bottom and top spaces.

In Run 2, under dynamic temperatures (Figure $4 b$ ), the concentration showed similar trends overall to those observed in the static experiment (Run 1). However, the temperature clearly affected both the bottom and top fluxes. The bottom flux showed the recently discovered water-induced inverse correlation with temperature [31], as indicated, for example, by the arrows at approximately 30-90 $\mathrm{min}$, where the flux increased and then decreased with decreasing and increasing temperature, respectively. Additionally, the difference between the maximum and minimum fluxes in that time period was as much as an order of magnitude. By contrast, the top flux was positively correlated with temperature, as indicated, for example, by the arrows in the same time period, where significant negative fluxes from the top space into the soil occurred, and the difference between the maximum and minimum fluxes exceeded an order of magnitude. The large changes in both the bottom and top fluxes, as well as the appearance of the inverse correlation and negative fluxes, were unexpected and cannot be explained by the temperature dependence of the diffusion coefficient of benzene in the air (Figure 1). Thus, the results demonstrated that larger flux changes occurred in wet soil under dynamic temperatures. 
(a) Run 1: Benzene, 10 wt\% water content

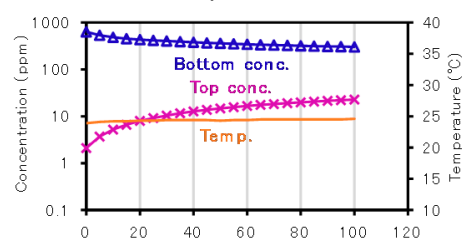

(b) Run 2: Benzene, 10 wt\% water content
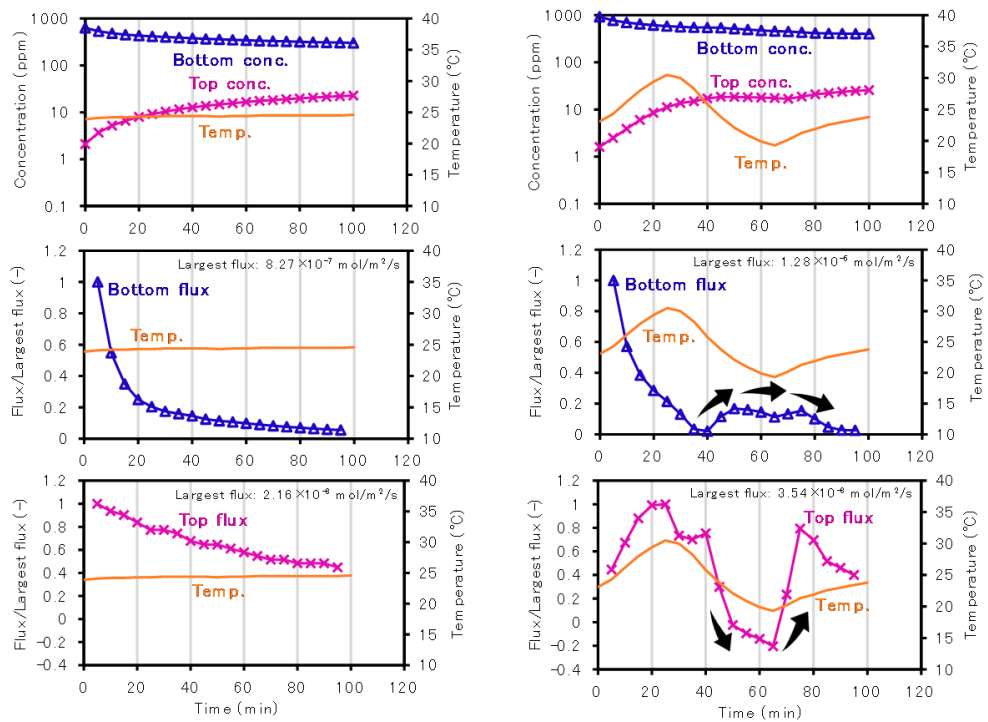

Figure 4. Top and bottom benzene concentrations and corresponding top and bottom benzene fluxes in (a) static temperature experiment (Run 1) and (b) dynamic temperature experiment (Run 2) at $10 \mathrm{wt} \%$ water content.

\subsection{Effects of Water Content and VOC Type on the Increase in Flux Change}

Figure 5 compares the benzene concentration and the corresponding flux in the dynamic temperature experiments at $10 \mathrm{wt} \%$ water content (Run 2) and $5 \mathrm{wt} \%$ water content (Run 3) and in the air-dried condition (approximately $0.3 \mathrm{wt} \%$ water content, Run 4). The bottom and top VOC concentrations changed more rapidly with decreasing water contents; therefore, the corresponding fluxes were larger at lower water contents, which was consistent with the well-known negative impact of water content on the rate of the diffusive gas-phase VOC transport in soil [38-40]. At all water contents, the bottom VOC flux was inversely correlated with the temperature, as indicated by the arrows. However, the strength of the inverse correlation, and thus the flux change, decreased significantly with decreasing water contents, as suggested by a previous study that reported an inverse correlation for benzene flux in fine- and coarse-grained silica sands at $10 \mathrm{wt} \%$ water content and in the air-dried condition [31]. For instance, the maximum and minimum bottom fluxes at 30-90 $\mathrm{min}$ for a $5 \mathrm{wt} \%$ water content differed by a factor of approximately 2 (Figure $5 b$ ), whereas the difference was as high as an order of magnitude at $10 \mathrm{wt} \%$, as stated previously (Figure 5a). The top VOC flux, which was correlated with temperature, as indicated by the arrows, also decreased with decreasing water contents. The difference between the maximum and minimum fluxes, which exceeded an order of magnitude at $10 \mathrm{wt} \%$ water content (Figure 5a), decreased to approximately 3 -fold at $5 \mathrm{wt} \%$ water content (Figure 5b) and was much smaller in the air-dried soil (Figure 5c). Although both the bottom and top VOC flux changes became smaller with decreasing water content, the changes at $5 \mathrm{wt} \%$ water content were still unexpectedly high in terms of the temperature dependence of the diffusion coefficient of benzene in the air (Figure 1). 
(a) Run 2: Benzene, 10 wt\% water content

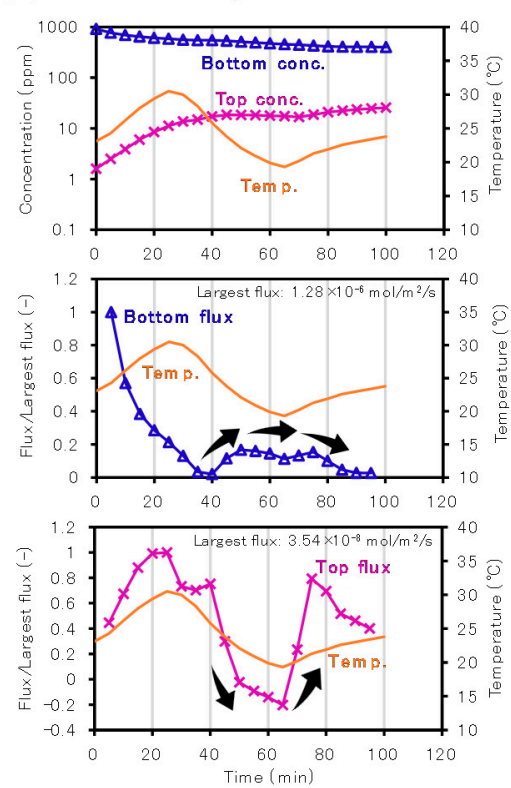

(b) Run 3: Benzene, 5 wt\% water content
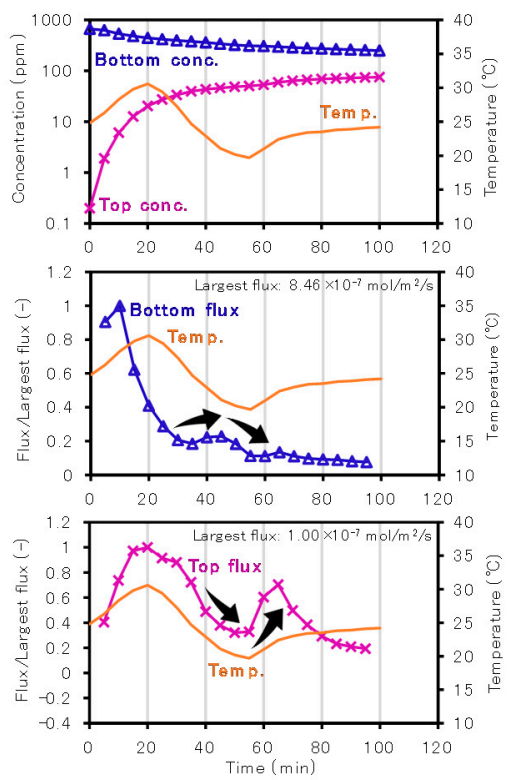

(c) Run 4: Benzene, air-dried
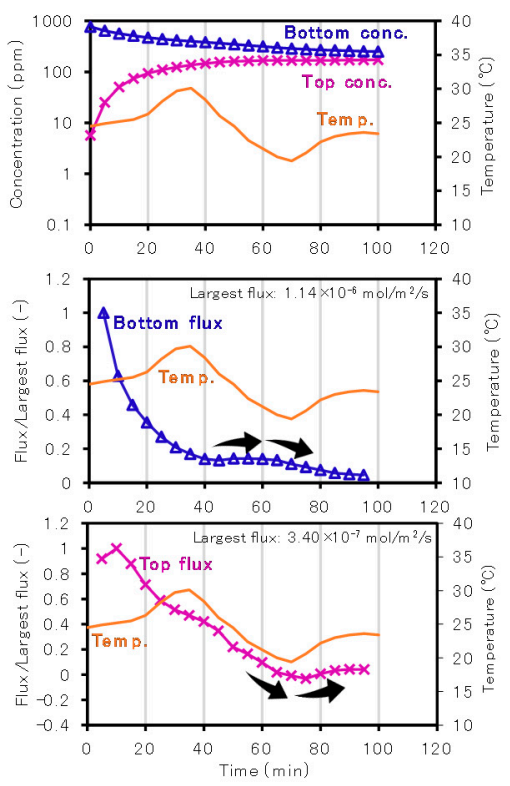

Figure 5. Top and bottom benzene concentrations and corresponding top and bottom benzene fluxes in dynamic temperature experiments: (a) Run 2 (10 wt \% water content), (b) Run 3 (5 wt \% water content), and (c) Run 4 (air-dried condition, $\sim 0.3 \mathrm{wt} \%$ water content).

Figure 6 compares the VOC concentration and the corresponding flux in the dynamic temperature experiments with benzene at $5 \mathrm{wt} \%$ water content (Run 3) and with TCE at $5 \mathrm{wt} \%$ water content (Run 5). Preliminary experiments at a constant temperature of $25^{\circ} \mathrm{C}$ indicated that the average effective diffusion coefficients for benzene and TCE in the silica sand at $5 \mathrm{wt} \%$ were similar, $9.3 \times 10^{-7}$ and $9.5 \times 10^{-7} \mathrm{~m}^{2} / \mathrm{s}$, respectively. This result was consistent with the fact that benzene and TCE have similar diffusion coefficients in the air (Figure 1). Consequently, the rates of change in the bottom and top concentrations, and thus the magnitudes of the bottom and top fluxes, of benzene and TCE were similar. Even in the TCE experiment, the bottom and top VOC fluxes exhibited inverse and positive correlations with temperature, respectively. However, the flux changes were larger for TCE. The maximum and minimum bottom fluxes of benzene at 30-90 min differed by a factor of approximately 2 (Figure 6a), whereas the TCE fluxes differed by a factor of approximately 5 (Figure $6 \mathrm{~b}$ ). By contrast, the maximum and minimum top fluxes of benzene during the same time differed by a factor of approximately 3 (Figure 6a), whereas the difference exceeded an order of magnitude for TCE (Figure 6b).

\section{Discussion}

The results reported above clearly demonstrate water-enhanced flux changes under dynamic temperatures, accompanied by an inverse correlation between temperatures and flux at deeper locations in vertical vapor-phase VOC diffusive transport in wet soils. As discussed in the introduction, this phenomenon was suggested by the results of previous field studies $[13,14]$, but it has not been investigated in laboratory experiments. Although the experimental results of our very recent study [31] showed that water-enhanced flux changes occurred, our report did not mention these changes because we focused on the water-induced inverse correlation. Additionally, our previous study used only one VOC (benzene) and wet condition (10 $\mathrm{wt} \%$ water content). Consequently, the present study proved the hypothesis that larger flux changes occurred for many types of VOC (or other volatile matters that contain inorganic materials such as mercury) in wet soils, where the strength of the effect increased with increasing water content, as discussed below. 
(a) Run 3: Benzene, 5 wty water content
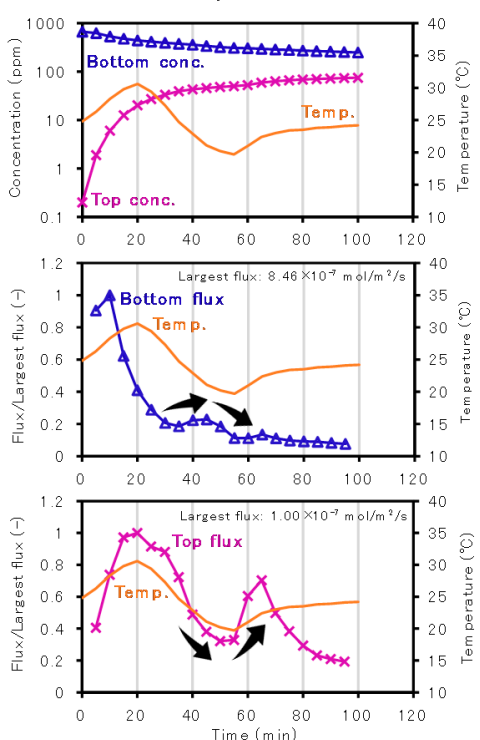

(b) Run 5: TCE, 5 wt* water content
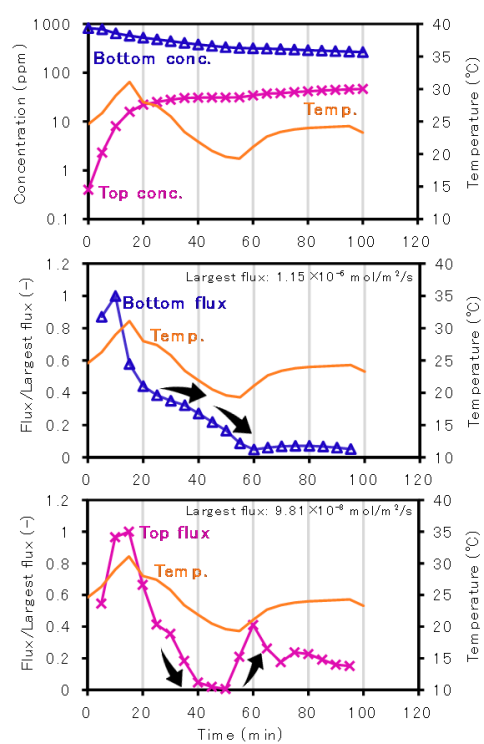

Figure 6. Top and bottom VOC concentrations and corresponding top and bottom VOC fluxes in dynamic temperature experiments: (a) Run 3 (benzene) and (b) Run 5 (TCE) at 5 wt\% water content.

We began by describing the mechanism of the water-enhanced flux changes accompanied by the water-induced inverse correlation. According to the hypothesis in our previous study [31], the inverse correlation and thus, the accompanying larger flux changes, should result from nonlinear vertical distributions of the vertical vapor-phase VOC concentration under dynamic temperatures owing to VOC volatilization from and dissolution in pore water, as illustrated in Figure 7. That is, the dynamic temperature precluded the occurrence of a linear concentration distribution, which might appear under static temperature (gray line in the figure). At higher temperatures, the VOC was volatilized from water, and water was also volatilized to induce further VOC volatilization. VOC was volatilized more rapidly when the initial vapor-phase VOC concentration and thus, the VOC partial pressure were lower because the difference between the pressure and saturated vapor pressure for the VOC was larger. By contrast, at lower temperatures, VOC was dissolved in water, and the water was also condensed to induce further VOC dissolution. The VOC dissolved more rapidly when the initial vapor-phase VOC concentration was higher owing to an increase in the difference between the liquid-phase concentration and solubility in water of the VOC due to cooling. By contrast, the concentrations near the soil surface and VOC source could not change as much as the temperature changed. The reason is that water near the soil surface has less effect when it is in contact with the dry atmosphere, and water near the VOC source has less effect because of the presence of water and air, which are saturated or nearly saturated with the VOC. Consequently, the distribution of the vapor-phase VOC concentration became nonlinear, as indicated by the red and blue lines during increasing and decreasing temperatures, respectively. Therefore, the vaporphase VOC concentration gradient, which drove VOC diffusion, was inversely correlated with the temperature at deeper locations, which caused the inverse correlation between temperature and flux. At the same time, at shallower locations, the concentration gradient was positively correlated with the temperature, resulting in a positive correlation between the temperature and flux. Since the diffusion coefficients of VOCs in the air did not depend strongly on the temperatures (Figure 1), the concentration gradient was believed to be the primary cause of the larger flux changes and the accompanying inverse correlation under dynamic temperatures in wet soil. 


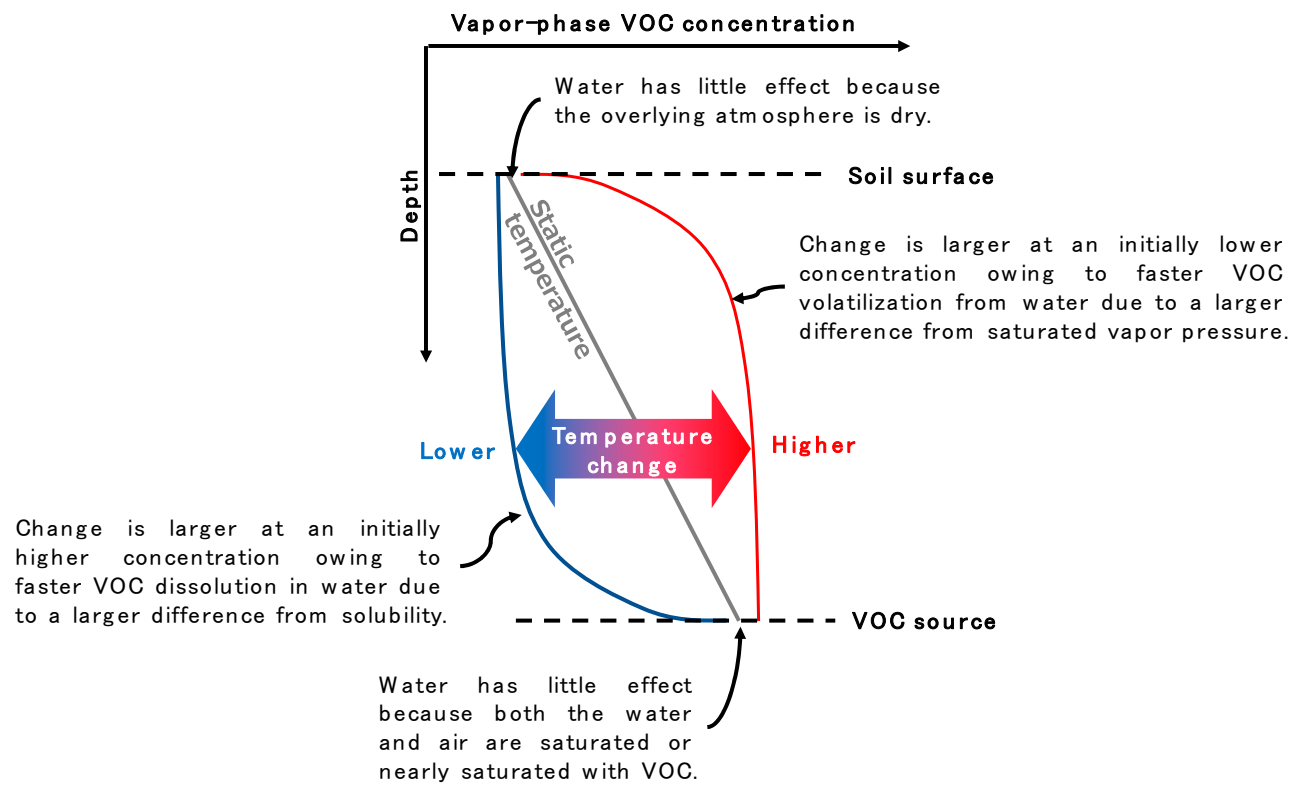

Figure 7. Mechanism of the larger changes in the vertical flux of a gas-phase VOC and inverse correlation with temperature at deeper locations; that is, a nonlinear vertical distribution of VOC concentration in wet soil under dynamic temperatures owing to VOC volatilization from and dissolution in pore water.

This mechanism was consistent with the experimental results, which showed that both the positive and inverse correlations with the flux had larger amplitudes at higher water contents. Additionally, the mechanism explained the experimental finding that the amplitude was larger for TCE than for benzene, considering that the temperature dependence of Henry's constant and thus the volatility of TCE were larger (Figure 8). Moreover, it was reasonable that previous field studies $[13,14]$ suggested larger flux changes for PCE in addition to TCE, considering that Henry's constant of PCE had a large temperature dependence (Figure 8). According to the mechanism, the strong temperature dependence of the volatility of VOCs was essential to the larger flux changes, suggesting that these flux changes were likely to occur for both organic and inorganic volatile matter. For instance, Henry's constant of mercury was much more temperature-dependent (Figure 8), further emphasizing the importance of extensive studies on the larger flux changes under dynamic temperatures in near-surface soil environments to obtain more reasonable estimates of the emission of VOCs and other important volatile matters of soils and its impact on the air quality and climate.

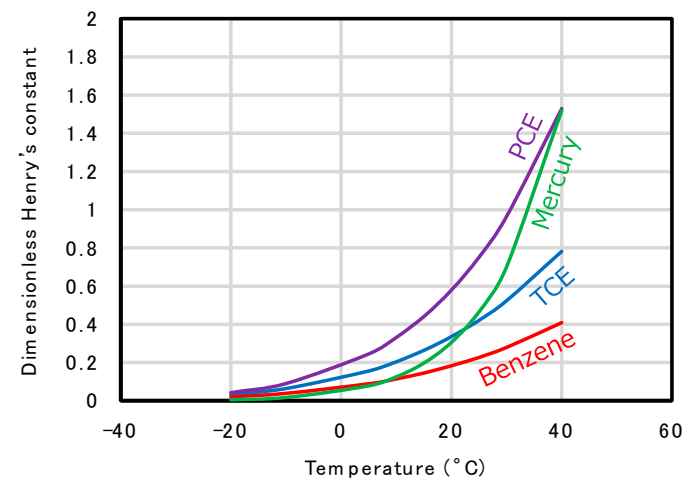

Figure 8. Temperature dependence of the dimensionless Henry's constant (concentration ratio) for benzene, TCE, PCE, and mercury [28]. 


\section{Conclusions}

Owing to the potential impacts of soil VOC emissions on the air quality and climate, it is highly important to quantitatively understand the transport behavior of VOCs in near-surface soils. It has been suggested in previous studies that temperature changes affect this transport behavior. However, the effects are not well understood. Indeed, much larger changes in the VOC flux under in situ dynamic temperatures than those expected from the temperature dependence of the diffusion coefficients of VOCs in the air have been suggested but have rarely been investigated experimentally so far. The present experimental study demonstrated that the larger changes in the VOC flux might originate from volatilization-dissolution interactions of VOCs with water. Future extensive studies on this newly discovered phenomenon are encouraged to better understand the impacts of the soil VOC emissions on the air quality and climate.

Author Contributions: Conceptualization, A.A.P., M.K., N.W. and K.N.; data curation, A.A.P. and M.K.; formal analysis, A.A.P., M.K. and N.W.; funding acquisition, A.A.P. and T.K.; investigation, A.A.P., M.K. and K.N.; methodology, A.A.P., N.W. and K.N.; project administration, N.W.; resources, N.W. and K.N.; supervision, T.K.; validation, M.Y. and J.W.; visualization, A.A.P., N.W. and M.Y.; writing-original draft, A.A.P. and N.W.; writing-review and editing, M.K., K.N. and J.W. All authors have read and agreed to the published version of the manuscript.

Funding: This research was supported by the Environment Research and Technology Development Fund (JPMEERF20191005) of the Environmental Restoration and Conservation Agency of Japan and by a scholarship from the Japanese ministry of Education, Culture, Sports, Science, and Technology (MEXT), grant number 173074.

Institutional Review Board Statement: Not applicable.

Informed Consent Statement: Not applicable.

Data Availability Statement: The original contributions presented in the study are included in the article, and further inquiries can be directed to the corresponding author.

Acknowledgments: This research was supported by the International Joint graduate Program in Resilience and Safety Studies, Tohoku University, Japan.

Conflicts of Interest: The authors declare no conflict of interest.

\section{References}

1. Roveda, L.; Polvara, E.; Invernizzi, M.; Capelli, L.; Sironi, S. Definition of an emission factor for VOC emitted from Italian and European refineries. Atmosphere 2020, 11, 564. [CrossRef]

2. Miyama, T.; Morishita, T.; Kominami, Y.; Noguchi, H.; Yasuda, Y.; Yoshifuji, N.; Okano, M.; Yamanoi, K.; Mizoguchi, Y.; Takanashi, S.; et al. Increases in biogenic volatile organic compound concentrations observed after rains at six forest sites in non-summer periods. Atmosphere 2020, 11, 1381. [CrossRef]

3. Stroud, C.A.; Ren, S.; Zhang, J.; Moran, M.D.; Akingunola, A.; Makar, P.A.; Munoz-Alpizar, R.; Leroyer, S.; Bélair, S.; Sills, D.; et al. Chemical analysis of surface-level ozone exceedances during the 2015 Pan American games. Atmosphere 2020, 11, 572. [CrossRef]

4. Churkina, g.; Kuik, F.; Bonn, B.; Lauer, A.; grote, R.; Tomiak, K.; Butler, T.M. Effect of VOC emissions from vegetation on air quality in Berlin during a heatwave. Environ. Sci. Technol. 2017, 51, 6120-6130. [CrossRef]

5. Rinnan, R.; Albers, C.N. Soil uptake of volatile organic compounds: Ubiquitous and underestimated? J. geophys.Res. Biogeosci. 2020, 125, e2020JG005773. [CrossRef]

6. Labianca, C.; De gisi, S.; Picardi, F.; Todaro, F.; Notarnicola, M. Remediation of a petroleum hydrocarbon-contaminated site by soil vapor extraction: A full-scale case study. Appl. Sci. 2020, 10, 4261. [CrossRef]

7. Liang, Q.; Bao, X.; Sun, Q.; Zhang, Q.; Zou, X.; Huang, C.; Shen, C.; Chu, Y. Imaging VOC distribution in cities and tracing VOC emission sources with a novel mobile proton transfer reaction mass spectrometer. Environ. Pollut. 2020, 265, 114628. [CrossRef]

8. Johnston, J.E.; gibson, J.M. Spatiotemporal variability of tetrachloroethylene in residential indoor air due to vapor intrusion: A longitudinal, community-based study. J. Expo. Sci. Environ. Epidemiol. 2014, 24, 564-571. [CrossRef] [PubMed]

9. United States Environmental Protection Agency. OSWER Technical guide for Assessing and Mitigating the Vapor Intrusion Pathway from Subsurface Vapor Sources to Indoor Air; EPA Office of Solid Waste and Emergency Response: Washington, DC, USA, 2015; pp. 2-154.

10. Shrader-Frechette, K.; Biondo, A.M. Health misinformation about toxic-site harm: The case for independent-party testing to confirm safety. Int. J. Environ. Res. Public Health 2021, 18, 3882. [CrossRef] 
11. Kponee, K.Z.; Nwanaji-Enwerem, J.C.; Fu, X.; Kakulu, I.I.; Weisskopf, M.G.; Jia, C. Elevated indoor volatile organic compound exposure in the Niger Delta Region of Nigeria. Int. J. Environ. Res. Public Health 2018, 15, 1939. [CrossRef]

12. Stefanakis, A.I. The fate of MTBE and BTEX in constructed wetlands. Appl. Sci. 2020, 10, 127. [CrossRef]

13. Bekele, D.N.; Naidu, R.; Chadalavada, S. Influence of spatial and temporal variability of subsurface soil moisture and temperature on vapour intrusion. Atmos. Environ. 2014, 88, 14-22. [CrossRef]

14. Barnes, D.L.; McRae, M.F. The predictable influence of soil temperature and barometric pressure changes on vapor intrusion. Atmos. Environ. 2017, 150, 15-23. [CrossRef]

15. Song, C.; Liu, B.; Dai, Q.; Li, H.; Mao, H. Temperature dependence and source apportionment of volatile organic compounds (VOCs) at an urban site on the north China plain. Atmos. Environ. 2019, 207, 167-181. [CrossRef]

16. Zhou, X.; Liu, Y.; Song, C.; Liu, J. Impact of temperature and microstructure on the emission characteristics of VOC in porous building materials. Procedia Eng. 2015, 121, 1067-1075. [CrossRef]

17. Bai, Y.; Huo, L.; Zhang, Y.; Liu, J.; Shao, H.; Wu, C.; guo, Z. A spatial fractional diffusion model for predicting the characteristics of VOCs emission in porous dry building material. Sci. Total Environ. 2020, 704, 135342. [CrossRef] [PubMed]

18. Du, P.; Sagehashi, M.; Terada, A.; Hosomi, M. Characterization of benzene emission to the atmosphere from contaminated soil. Environ. Sci. 2010, 23, 467-475.

19. Voudrias, E.A.; Li, C. Benzene vapor transport in unsaturated soil: Adequacy of the diffusion equation. J. Hazard. Mater. 1993, 34, 295-311. [CrossRef]

20. Lin, T.F.; Little, J.C.; Nazaroff, W.W. Transport and sorption of volatile organic compounds and water vapor within dry soil grains. Environ. Sci. Technol. 1994, 28, 322-330. [CrossRef] [PubMed]

21. Lin, T.F.; Loy, M.D.; Nazaroff, W.W. gas-phase transport and sorption of benzene in soil. Environ. Sci. Technol. 1996, 30, 2178-2186. [CrossRef]

22. Kim, J.Y.; Edil, T.B.; Park, J.K. Volatile organic compound (VOC) transport through compacted clay. J. Geotech. Geoenviron. 2001, 127, 126-134. [CrossRef]

23. Osagie, E.I.; Cn, O. Investigation of mixture effects on the adsorption rates of aromatics from aqueous solution on clay and sandy soil. Chem. Sci. J. 2015, 6, 1-5.

24. Cabbar, C.H.; Bostanci, A. Moisture effect on the transport of organic vapors in sand. J. Hazard. Mater. 2001, 82, 313-322. [CrossRef]

25. Cotel, S.; Schäfer, g.; Barthes, V.; Baussand, P. Effect of density-driven advection on trichloroethylene vapor diffusion in a porous medium. Vadose Zone J. 2011, 10, 565-581. [CrossRef]

26. Du, P.; Sagehashi, M.; Tarada, A.; Zhou, S.; Li, F.; Hosomi, M. Adequacy of a simple diffusion model to predict benzene behavior in soil. Soil Sci. Soc. Am. J. 2011, 75, 2147-2157. [CrossRef]

27. Bekele, D.N.; Naidu, R.; Chadalavada, S. Influence of soil properties on vapor-phase sorption of trichloroethylene. J. Hazard. Mater. 2016, 306, 34-40. [CrossRef]

28. United States Environmental Protection Agency. EPA On-Line Tools for Site Assessment Calculation. Available online: https: //www3.epa.gov/ceampubl/learn2model/part-two/onsite (accessed on 12 February 2021).

29. Shonnard, D.R.; Bell, R.L. Benzene emissions from a contaminated air-dry soil with fluctuations of soil temperature or RH. Environ. Sci. Technol. 1993, 27, 2909-2913. [CrossRef]

30. Ausma, S.; Edwards, g.C.; gillespie, T.J. Laboratory scale measurement of trace gas fluxes from land farm soils. J. Environ. Qual. 2003, 32, 8-22. [CrossRef] [PubMed]

31. Parlin, A.A.; Watanabe, N.; Nakamura, K.; Yamada, M.; Wang, J.; Komai, T. Water-induced inverse correlation between temperature and flux changes in vertical vapor-phase diffusive transport of volatile organic compounds in near-surface soil environments. Appl. Sci. 2021, 11, 3489. [CrossRef]

32. Huang, C.W. Study on Particle Breakage of Sands Subjected to Various Confining Stress and Shear Strain Levels. Ph.D. Thesis, Tokyo Metropolitan University, Tokyo, Japan, 30 September 2015.

33. Nakarai, K.; Yoshida, T. Effect of carbonation on strength development of cement-treated Toyoura silica sand. Soils Found. 2015, 55, 857-865. [CrossRef]

34. Simatupang, M.; Sukri, A.S.; Putri, T.S. Effect of confining pressures on the shear modulus of sand treated with enzymatically induced calcite precipitation. IOP Conf. Ser. Mater. Sci. Eng. 2019, 615, 012042. [CrossRef]

35. Kimura, S.; Kaneko, H.; Ito, T.; minagawa, H. Investigation of fault permeability in sands with different mineral compositions (evaluation of gas hydrate reservoir). Energies 2015, 8, 7202-7223. [CrossRef]

36. Kajiyama, S.; Nakata, Y.; Miyamoto, R.; Taue, M. Study on the shear band of sand with various particle characteristics using PIV analysis. E3S Web Conf. 2019, 92, 06005. [CrossRef]

37. Siegrist, R.L. Volatile organic compounds in contaminated soils: The nature and validity of the measurement process. J. Hazard. Mater. 1991, 29, 3-15. [CrossRef]

38. Gao, W.; Liu, F.; Chan, H. gas phase effective diffusion coefficient of gasoline and characteristic components in dry fine sand. In Proceedings of the 2009 3rd International Conference on Bioinformatics and Biomedical Engineering, Beijing, China, 11-13 June 2009. 
39. Bartelt-Hunt, S.L.; Smith, J.A. Measurement of effective air diffusion coefficients for trichloroethene in undisturbed soil cores. J. Contam. Hydrol. 2002, 56, 193-208. [CrossRef]

40. Batterman, S.; Padmanabham, I.; Milne, P. Effective gas-phase diffusion coefficients in soils at varying water content measured using a one-flow sorbent-based technique. Environ. Sci. Technol. 1996, 30, 770778. [CrossRef] 